\title{
The influence of climate change and anthropogenic activities on annual runoff of Huangfuchuan basin in northwest China
}

\author{
Yuanyuan Zhou • Changxing Shi • Xiaoli Fan • \\ Wenwei Shao
}

Received: 9 September 2012 / Accepted: 15 April 2014 / Published online: 2 May 2014

(C) Springer-Verlag Wien 2014

\begin{abstract}
In recent years, climate change and anthropogenic activities have threatened the water supply in the middle reaches of the Yellow River, prompting this study into the variation of water resources and the influencing factors, taking the Huangfuchuan basin as an example. Firstly, changes in climatic aridity and annual runoff in the Huangfuchuan basin from 1956 to 2009 were analysed. Then, the influence of changes in climatic aridity, water use for irrigation and soil conservation measures were calculated using an analysis of principal components regression. The results show that climatic aridity has increased in the recent three decades with two abrupt changes around 1961 and 1998, and that annual runoff has decreased continually with two abrupt changes around 1979 and 1999. The rapid development of sediment check dams in the 1970s could be the reason for the abrupt change around 1979. The abrupt change around 1999 could be the result of both the intensification of changes in climatic aridity and the large-scale construction of water and soil conservation measures after 1983, the further improvement of these measures after 1993 and ecological restoration measures of converting cropland to forest implemented since 1997. By quantifying the effects of those factors that influence runoff variation, it was found that anthropogenic activities were more important than climate change in the two periods between 1979-1998 and 1999-2006, but the influence of changes in climatic aridity increased from the first to the second period. For the runoff reduction related to anthropogenic activities, the primary cause
\end{abstract}

Y. Zhou $\cdot$ C. Shi $(\varangle) \cdot$ X. Fan $\cdot$ W. Shao

Key Laboratory of Water Cycle and Related Land Surface Processes, Institute of Geographic Sciences and Natural Resources Research, CAS, Beijing 100101, China

e-mail: shicx@igsnrr.ac.cn

Y. Zhou $\cdot$ X. Fan $\cdot$ W. Shao

Graduate University of Chinese Academy of Sciences,

Beijing 100049, China was water diversion for irrigation in the first period, and it was soil conservation measures in the second period.

\section{Introduction}

Owing to climate change and anthropogenic activities, the global water crisis has become more severe in recent decades (Frederick and Major 1997; Barnett et al. 2005; Rogers 2008). Climate change will raise temperatures (and possibly evaporation), which could contribute to reduced river flow (Rogers 2008), early snowmelt (Grafton et al. 2013), and drought. This would have implications for reservoir storage capacity and operation, and for the availability of stored water for domestic and agricultural use (Grafton et al. 2013). Growing populations need more water for drinking, hygiene, sanitation, food production and industry. Over-extraction of groundwater for dairy farming has 'destroyed' local resources in Gujarat in India (Jim 2006). As early as 1987, the correlation between climate change and water resources was proposed in a report by the World Meteorological Organization. In the second and third reports of the Intergovernmental Panel on Climate Change (IPCC), the impact of climate change on water resources attracted significant attention. The understanding of the impact of anthropogenic activities on water resources has been increasing since the publication of the second IPCC report (Houghton et al. 1997a, b), which identified that the influence of anthropogenic activities in non-negligible.

Many studies have investigated the impact of climate change on hydrology and water resources in many regions (Alan and Dennis 1999; Xu 2000; Middelkoop et al. 2001; Niklas et al. 2004; Mall et al. 2006; Edossa et al. 2010). Work published by the US Water Resources Council (1978) showed that in humid regions of the US to the east of the 100th meridian, warming of $2{ }^{\circ} \mathrm{C}$ and a $10 \%$ reduction in precipitation would not have serious effects, whereas in the west, the 
impact of similar changes would be severe in seven arid and semiarid regions (Revelle and Waggoner 1983). Following an analysis of the main climatic belts, Arnell et al. (1996) also found that water resources were more sensitive to climate change in arid and semiarid sites (refer to Anthony 1999). Magadza (2000) highlighted that an increase in climatic aridity would enhance the risk of arid and semiarid regions of Africa to water supply vulnerabilities. Using the A2 scenario with general circulation models and an artificial neural network, Zarghami et al. (2011) determined that frequent shifts from semiarid to arid climate in the East Azerbaijan Province of Iran, have threatened the water supply in recent years.

The middle reaches of the Yellow River are located in arid and semiarid regions. However, few studies have been performed on the influence of changes in climatic aridity on hydrology and water resources. Previous studies have focused on investigating the correlation between meteorological factors (usually only precipitation) and runoff using statistical analyses or numerical model simulations (Wang et al. 2006a; Zhang et al. 2009; Xu and Wang 2010; Liu and Cui 2011). Woodhouse and Overpeck (1998) claimed that change in climatic aridity is a natural response to climate warming in some regions of the world and one that has an important effect on water supply. The degree of climatic aridity can be quantified using an aridity index, which was reviewed in detail by Oliver (2005). This study investigates changes in climatic aridity using a simple aridity index based on the tendency analyses of meteorological factors and their impacts on runoff.

In the middle reaches of the Yellow River, the main anthropogenic activities that might have noticeable impact on runoff are water use and soil conservation measures, including terracing, sediment check dams, forestation, grass sowing and irrigation. The contributions of these measures to runoff change have been analysed by many scholars using hydrologic modelling and soil conservation methods (Xu 2004; Ran 2006; Wang et al. 2006a; Mu et al. 2007; Zhang et al. 2010). The former determines the gross impact by examining the changes in runoff in relation to climate factors, mainly precipitation, for a watershed in which water and soil conservation measures have been implemented. The latter evaluates the total impact through estimating the contribution of each type of water and soil conservation measure based on plot experiments. However, a consensus on this issue has not yet been achieved. Mu et al. (2007) thought that water and soil conservation measures were the principal factors driving runoff reduction on the Loess Plateau in the Hekouzhen-Longmen reach of the Yellow River. The results of Zhi et al. (2009) showed that land use and climate change decreased runoff on the Loess Plateau by 9.6 and $95.8 \%$, respectively, during 1981-2000. $\mathrm{Xu}$ (2011) found that 78.6 and $72.9 \%$ of the variations in the measured annual runoff and natural runoff, respectively, could be explained by variations in annual precipitation during 1956-1971. These values decreased to 42.5 and $50.2 \%$, respectively, after soil and water conservation measures were implemented during 1972-1996. Considering a large tributary in the middle reaches of the Yellow River as an example, the present study investigates this issue through a quantitative assessment of the contributions of aridity variation, water use and soil and water conservation measures on runoff reduction by constructing a new formula based on mechanism analysis.

\section{Study area, dataset and methods}

\subsection{Study area}

The Huangfuchuan River is a major tributary and one of the main sources of coarse sand in the middle reaches of the Yellow River (Fig. 1). It originates from Jungar Banner in the Inner Mongolia Autonomous Region and flows into the Yellow River at Fugu, Shaanxi Province (Xu et al. 2011). The hydrological station furthest downstream is Huangfu station, above which the drainage basin area encompasses $3,246 \mathrm{~km}^{2}$ and the length of the river is $137 \mathrm{~km}$ (Sui et al. 2008). In the middle of the basin are 11 villages, covering an area of $2,798 \mathrm{~km}^{2}$ of Jungar Banner, which comprises $86.2 \%$ of the basin. In the south, there are seven villages of Fugu County covering an area of $415 \mathrm{~km}^{2}$, which constitutes $12.8 \%$ of the basin. The remaining area of $33 \mathrm{~km}^{2}$ in the north is a part of Dalad Banner. With sparse population and extensive natural grassland, the northern, central and western parts of the basin are suited for stock farming. Agriculture dominates the southeastern part where the population density is $1-2.5$ times larger than that in the central and western regions (Jiang et al. 2003).

In the Huangfuchuan basin, the annual mean temperature is 6.2-7.2 ${ }^{\circ} \mathrm{C}$, increasing from west to east, and the sunshine duration exceeds $3,000 \mathrm{~h}$ per year. The annual mean precipitation is $350-450 \mathrm{~mm}, 80 \%$ of which falls in the four months from June to September. An annual mean runoff of $4.25 \mathrm{~m}^{3} / \mathrm{s}$ was recorded in the period of 1954-2009 (Gao et al. 2005).

Due to sparse vegetation, thick and highly erodible loess, uneven seasonal distribution of rainfall, relatively high intensity of rainstorms and irrational anthropogenic activities, soil erosion in the Huangfuchuan watershed has created serious damage. Since the mid-1950s, water and soil conservation measures have been undertaken in this watershed. Prior to the 1970 s, soil conservation measures included mainly grass sowing and afforestation of small areas. According to statistical data, the area of afforestation and grass sowing accounted for $86.3 \%$ of the area in which soil conservation measures were applied, which, at that time, occupied just $6.7 \%$ of the entire basin. Sediment check dams were built on a large scale in the 1970s and further soil conservation measures were implemented after 1983 when the basin was listed as one of the national key basins requiring soil erosion control. By the 
Fig. 1 Map of the study area, the inset showing the location of the Huangfuchuan basin

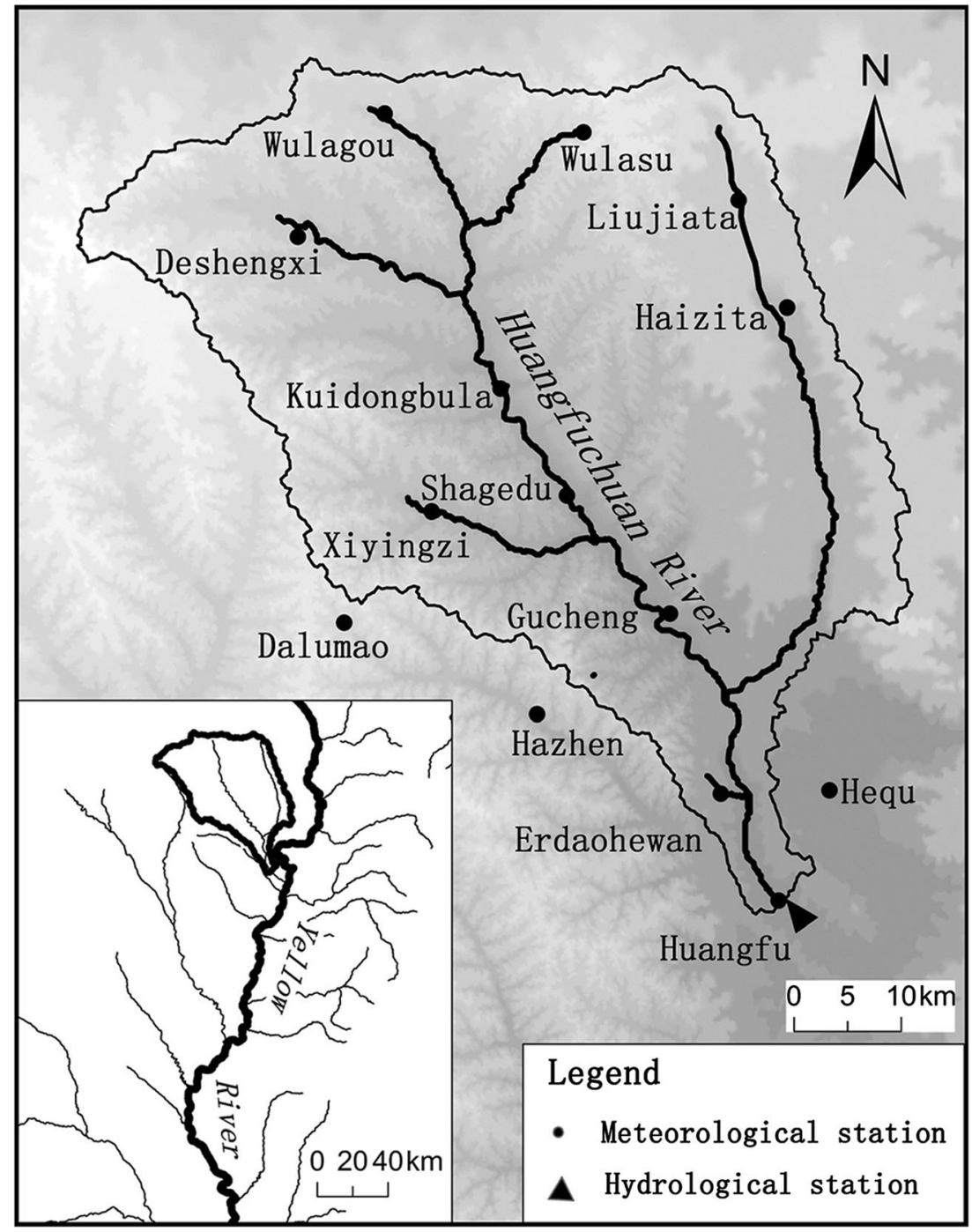

end of the 1980s, the proportion of controlled area was $16.7 \%$ of the basin, of which areas of grass and forest conservation measures accounted for $90 \%$. As a national key basin, the second phase of soil erosion control began in 1993. The controlled area increased to $28.2 \%$ by the end of 1997 . At the end of 2006, an area of $1,765 \mathrm{~km}^{2}$ had been controlled with engineering and biological measures accounting for 2.4 and $97.6 \%$, respectively (Zhu et al. 2003; Wang et al. 2011).

\subsection{Data and methods}

The annual runoff at Huangfu station was obtained from the Yellow River Water Yearbook and the Yellow River Water Resources Bulletin. The daily precipitation and temperature data, recorded at the meteorological stations used in this research (Fig. 1), were supplied by the Yellow River Water Conservancy Commission and the China Meteorological Data Sharing Service System. The period of the runoff and meteorological records extended from 1956 to 2009 . To estimate the spatial field of annual precipitation and annual temperature, spatial interpolation was performed by kriging. The data of water and soil conservation measures and water use were obtained from the studies by Wang and Zhu (2002), Zhu et al. (2003) and Wang et al. (2011), including the areas of terracing, sediment check dams, forestation and grass sowing. The principal form of water use within the basin is water diversion for irrigation and therefore, the area of irrigated land was used to represent the influence of water use. The principal anthropogenic activities in different periods are listed in Table 1.

Using the meteorological data, the De Martonne aridity index was calculated for the period of 1956-2009. A MannKendall (Mann 1945; Kendall 1975) test was used to examine the significance of tendency of the series. Three methods were used to diagnose abrupt changes in the series of runoff and climatic factors: the sequential cluster (Ding 1986), Pettitt (Pettitt 1979) and Lee-Heghinian (Lee and Heghinian 1977) tests. A further two methods were employed to build a linear 
Table 1 The main human activities in five periods

\begin{tabular}{llllll}
\hline Periods & Sediment check dams & Terraces & Irrigation & Forestation & $\begin{array}{l}\mathrm{hm}^{2} \\
\text { Grass sowing }\end{array}$ \\
\hline $1959-1968$ & 68 & 481 & 610 & 4,011 & 405 \\
$1969-1978$ & 317 & 1,048 & 655 & 9,936 & 1,924 \\
$1979-1988$ & 562 & 1,744 & 1,444 & 36,379 & 10,555 \\
$1989-1998$ & 1,470 & 4,519 & 1,905 & 73,541 & 31,865 \\
$1999-2006$ & 1,271 & 2,190 & 2,390 & 100,830 & 38,992
\end{tabular}

runoff model. All seven methods are explained simply in the following.

\section{(1) Mann-Kendall (MK)}

The non-parametric MK statistical test is based on the correlation between the ranks of a time series and their time order (Mann 1945; Kendall 1975; Li et al. 2007). It is assumed that the time series are independent. For a time series $\left\{x_{\mathrm{t}}, t=1,2, \ldots, n\right\}$, the test statistic $S$ is given by

$S=\sum_{i=1}^{n-1} \sum_{j=i+1}^{n} a_{i j}$

$a_{\mathrm{ij}}=\operatorname{sign}\left(x_{\mathrm{j}}-x_{\mathrm{i}}\right)=\operatorname{sign}\left(R_{\mathrm{j}}-R_{\mathrm{i}}\right)=\left\{\begin{aligned} 1, & x_{\mathrm{j}}-x_{\mathrm{i}}>0 \\ 0, & x_{\mathrm{j}}-x_{\mathrm{i}}=0 \\ -1, & x_{\mathrm{j}}-x_{\mathrm{i}}<0\end{aligned}\right.$

where $R_{\mathrm{i}}$ and $R_{\mathrm{j}}$ are the ranks of observations $x_{\mathrm{i}}$ and $x_{\mathrm{j}}$ of the time series, respectively.

Under the assumption that data are independent and identically distributed, the mean and variance of the $S$ statistic $(E(S)$ and $V(S))$ are given by

$E(S)=0$

$V(S)=n(n-1)(2 n+5) / 18$

where $n$ is the number of observations.

The original MK statistic, designated by $Z$, can be computed as

$Z=\left\{\begin{array}{cc}(S-1) / \sqrt{\mathrm{V}(S)}, & S>0 \\ 0, & S=0 \\ (S+1) / \sqrt{\mathrm{V}(S)}, & S<0\end{array}\right.$

If $-Z_{1-\mathrm{a} / 2} \leq Z \leq Z_{1-\mathrm{a} / 2}$, then the null hypothesis of no trend can be accepted at a significance level of $a$; otherwise, the null hypothesis can be rejected and an alternative hypothesis can be accepted at the significance level of $a$.

The null hypothesis for the MK test can only be valid if the data are independent and randomly ordered. Cox and Stuart (1955) thought that the existence of a positive serial correlation increases the possibility of the MK test detecting a trend that does not exist. Yue et al. (2000) demonstrated that the existence of a positive serial correlation would cause an overestimation of the probability of trend and vice versa. In this study, to guarantee a real trend being detected, the autocorrelation (lag 1) of the time series is verified by the Dubin-Watson (DW) test. According to the frequency distribution table of the DW test statistics, the lower and upper bounds are $1.53\left(d_{\mathrm{L}}\right)$ and $1.6\left(d_{\mathrm{U}}\right)$, respectively, at a significance level of 0.05 . DW indices (lag 1 autocorrelation) of the precipitation and temperature series are 2.01 and 2.143 , respectively, which are smaller than 2.47 (or $4-d_{\mathrm{L}}$ ). This shows that both series are independent.

(2) Sequential cluster

Sequential cluster is based on an orderly classification approach (Ding 1986). In essence, it estimates the optimal dividing point that has the smallest sum of squared residuals, expressed as $S_{\mathrm{n}}(\tau)$, in the two groups before and after the point of interest. $S_{\mathrm{n}}(\tau)$ is given by

$$
S_{\mathrm{n}}(\tau)=V_{\mathrm{r}}+V_{\mathrm{n}-\mathrm{r}}=\sum\left(x_{\mathrm{i}}-\bar{x}_{\tau}\right)^{2}+\sum\left(x_{\mathrm{i}}-\bar{x}_{\mathrm{n}-\tau}\right)^{2}, \quad 1 \leq \tau \leq n
$$

where $\bar{x}_{\tau}$ and $\bar{x}_{\mathrm{n}-\tau}$ are the means, and $V_{\mathrm{r}}$ and $V_{\mathrm{n}-\mathrm{r}}$ are the squared residuals before and after point $\tau$, respectively.

(3) Pettitt test

The Pettitt test is a non-parametric approach (Pettitt 1979). It constructs the statistic $U_{\mathrm{t}, \mathrm{N}}$ :

$U_{\mathrm{t}, \mathrm{N}}=U_{\mathrm{t}-1, \mathrm{~N}}+\sum_{\mathrm{j}=1}^{\mathrm{N}} \operatorname{sgn}\left(x_{\mathrm{t}}-x_{\mathrm{i}}\right) ; \quad t=2,3, \ldots, N$

$\operatorname{sgn}\left(x_{\mathrm{t}}-x_{\mathrm{i}}\right)=\left\{\begin{array}{rr}1, & x_{\mathrm{t}}-x_{\mathrm{i}}>0 \\ 0, & x_{\mathrm{t}}-x_{\mathrm{i}}=0 \\ -1, & x_{\mathrm{t}}-x_{\mathrm{i}}<0\end{array}\right.$

The abrupt change appears at the point with maximum $K_{\mathrm{t}, \mathrm{N}}$, which is the absolute value of the statistic $U_{\mathrm{t}, \mathrm{N}}$. The value of $p$ is used to estimate the significance of the change point. $K_{\mathrm{t}, \mathrm{N}}$ and $p$ are given by

$K_{\mathrm{t}, \mathrm{N}}=\max \left|U_{\mathrm{t}, \mathrm{N}}\right|, 1 \leq t \leq N ; \quad p \cong 2 \exp \left\{-6 K_{\mathrm{t}, \mathrm{N}}{ }^{2} /\left(N^{3}+N^{2}\right)\right\}$

A point is considered an abrupt change point for $p \leq 0.5$. 
(4) Lee-Heghinian

The Lee-Heghinian test is based on the theory of Bayes (Lee and Heghinian 1977). It is assumed that the population follows a Gaussian distribution and that the prior distribution of abrupt changes is a uniform distribution. Through calculating the posterior distribution $f(\tau)$ of all points in a series, abrupt changes can be identified from the peaks of the curve of $f(\tau)$, which is given by

$$
\begin{gathered}
f\left(\tau \mid x_{1}, x_{2}, \cdots, x_{\mathrm{n}}\right)=k[n / \tau(n-\tau)]^{\varphi}[R(\tau)]^{-(n-2) / 2} \\
R(\tau)=\left[\sum_{\mathrm{t}=1}^{\tau}\left(x_{\mathrm{t}}-\bar{x}_{\tau}\right)^{2}+\sum_{\mathrm{t}=\tau+1}^{n}\left(x_{\mathrm{t}}-\bar{x}_{\mathrm{n}-\tau}\right)^{2}\right] \\
/ \sum_{t=1}^{n}\left(x_{\mathrm{t}}-\bar{x}_{\tau}\right)^{2} ; 1 \leq \tau \leq n-1
\end{gathered}
$$

(5) Principal component regression

Principal component regression (Jolliffe 1986) is used to deal with the high correlation amongst the influencing factors when constructing the models between runoff and the influencing factors. It is a combination of principal components analysis and regression analysis. The principal components analysis of the time series of all the influencing factors selects the lowest number of principal components that have the largest percentage of variance and a total variance percentage close to or greater than $70 \%$ (Jolliffe 1986; Ferre 1995). Then, the runoff coefficient is related to the selected principal components through regression analysis. Finally, the coefficient of each factor and constant term are established by reverting the principal components to the influencing factors.

(6) De Martonne aridity index

A suggestive indicator for the characterisation of aridity was proposed by De Martonne (1926). It requires minimal data, as described by the following equation:

$I=\frac{P}{T+10}$

where $P$ is the mean annual precipitation $(\mathrm{mm})$ and $T$ is the mean annual temperature $\left({ }^{\circ} \mathrm{C}\right)$. The denominator contains an additional value of $10{ }^{\circ} \mathrm{C}$ to produce positive results in regions with negative average annual temperatures, such as mountainous regions or deserts in the middle latitudes (Lungu et al. 2011). The climate is classified as humid, semiarid or arid depending on whether the value of $I$ is greater than 20, 10-20 or below 10, respectively (Alizadeh 2001; Neira Mendez 2005). Equation (12) suggests that the degree of climatic aridity is influenced by both precipitation and temperature.

(7) Linear runoff model

The ratio of annual runoff to annual precipitation, or runoff coefficient $(R C)$, provides a measure of a basin's water yield (Guardiola et al. 2011). Hence, it is used here to analyse the relationship between runoff variation and the influencing factors. According to the mechanism of runoff generation, a linear runoff model is constructed as follows:

$R C=\beta+\sigma_{\mathrm{j}} X_{\mathrm{j}}$

where $X_{\mathrm{j}}$ represents the influencing factors, and $\beta$ and $\sigma_{\mathrm{j}}$ are coefficients.

The influencing factors include climate change, indicated by the aridity index, and anthropogenic activities. In the Huangfuchuan basin, soil conservation measures and water use for irrigation are the principal anthropogenic activities that affect the processes of runoff generation. Soil conservation measures primarily include terracing, sediment check dams, forestation and grass sowing. These measures alter the processes of runoff generation by increasing the infiltration capacity of slopes and intercepting runoff in river channels. Because the areas assigned to these measures have increased with time, they are highly correlated with each other and their real contributions to runoff cannot be revealed by regression analysis. Therefore, in this study, a weighted area is used instead of the area of each type of water and soil conservation measure. According to Zhang et al. (1994), the capacity of runoff interception of terraces, sediment check dams, forests and grass on the Loess Plateau is 700.5, 4500, 199.5 and $150 \mathrm{~m}^{3} \mathrm{ha}^{-1}$, respectively. Thus, assuming a weight of 1 for the terraces, the weights of the sediment check dams, forests and grass would be 4500/700.5, 199.5/700.5 and 150/700.5, respectively.

\section{Results}

\subsection{Changes in climate and runoff}

\subsubsection{Trends of meteorological factors}

The trends of precipitation and temperature in the study area from 1956 to 2009 are displayed in Fig. 2.

The slopes of the trend lines reveal that precipitation decreased by $1.52 \mathrm{~mm} / \mathrm{a}$ and that temperature rose by $0.02{ }^{\circ} \mathrm{C}$ in this period. The MK test statistic for the temperature series is 3 , indicating a significant increasing tendency, whereas it is -1.86 for the precipitation series, suggesting that the visually discernible negative trend is not statistically significant.

To study the trend of climate change, the period from 1956 to 2009 was divided into five intervals: $1956-1969,1970$ 1979, 1980-1989, 1990-1999 and 2000-2009. The means of precipitation and temperature in each period were calculated 

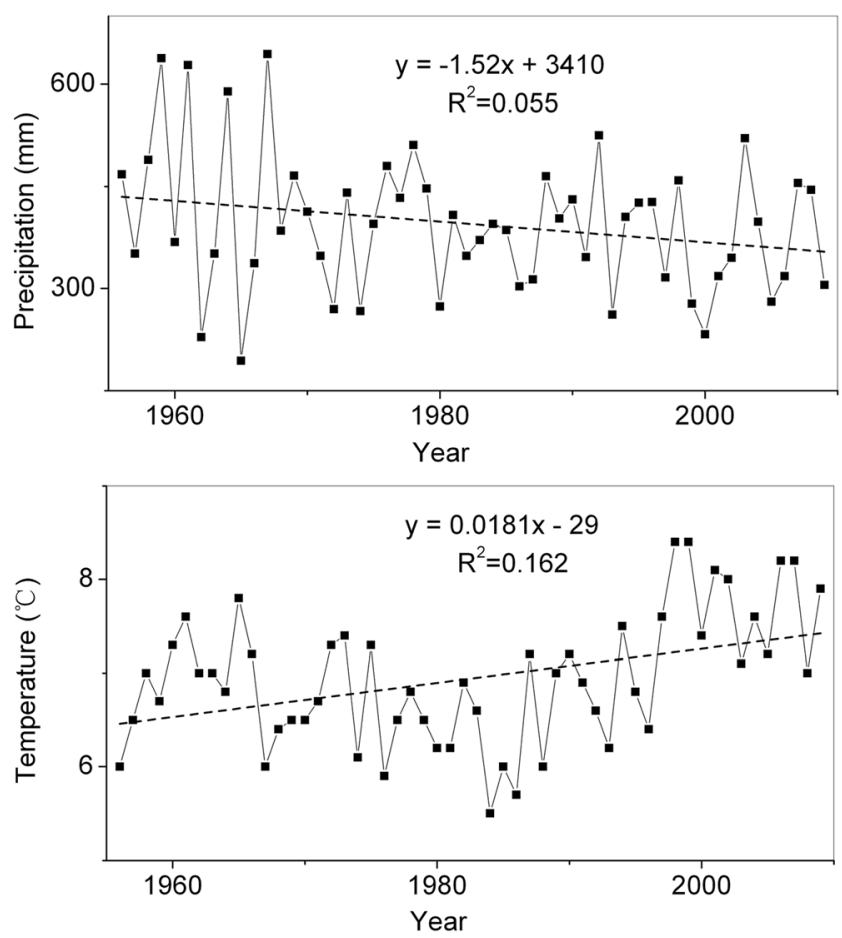

Fig. 2 Changes in annual precipitation and temperature in the Huangfuchuan basin from 1956 to 2009

and they are presented in Table 1. It can be seen that the temperature exceeded the 54-year average, but that precipitation was less than the 54-year average in the two decades after 1990.

Precipitation exhibits a negative trend with a much larger variance during the period from the 1950s to the 1960s and similar results have been presented Wang et al. (2006b), Sui et al. (2008), and Yin et al. (2009). Temperature shows a downward trend in the period from the 1950s to the 1970s. According to Tang et al. (2009) and Chen et al. (2013), this was a cold period around the world. Since the 1980s, global temperature has been increasing (Houghton 2007). Chen et al. (2013) have stated their viewpoint that solar activity, volcanic activity and sea-air exchange are the reasons behind climatic variation.

\subsubsection{Trend of climatic aridity variation}

The decreasing trend of $I$, calculated by Eq. (12), is shown clearly in Fig. 3, indicating the aggravation of climatic aridity in the Huangfuchuan watershed during the past 54 years. The mean of aridity index $I$ in each decade is listed in Table 2. It can be seen that the values of $I$ in the three decades after 1980 are less than the 54-year average.

\subsubsection{Trend of runoff}

As shown in Fig. 4, runoff exhibits a negative trend in the period from 1956 to 2009 with an average rate of decline of

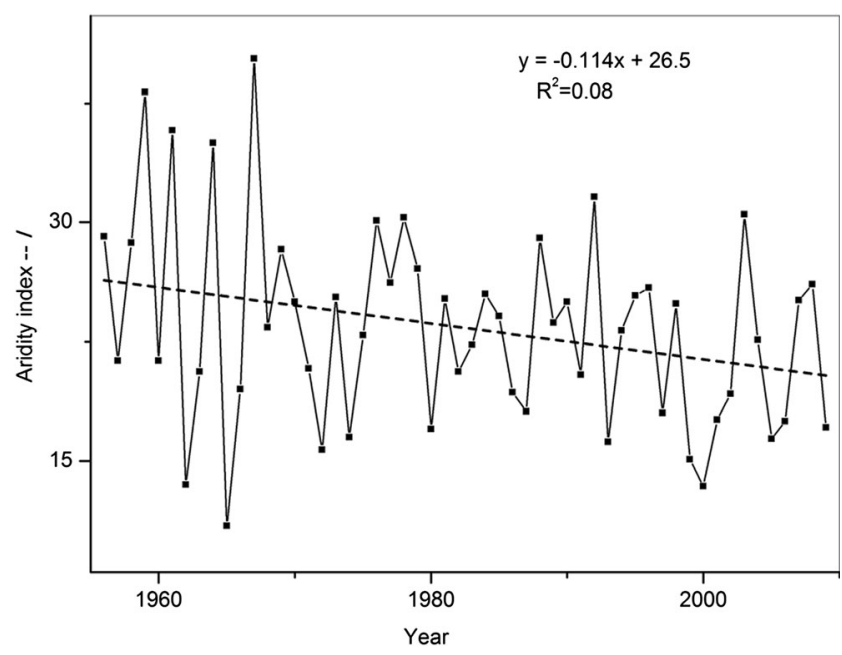

Fig. 3 Changes in aridity index $(I)$ in the Huangfuchuan basin from 1956 to 2009

$0.11 \mathrm{~m}^{3} / \mathrm{s} / \mathrm{a}$. The mean runoff in each period is given in Table 1. It can be seen that runoff declined substantially in the two decades after 1990 and that the average runoff of the last decade was $73 \%$ less than the 54-year average.

\subsection{Abrupt changes in runoff and meteorological factors}

\subsubsection{Abrupt changes in runoff}

The abrupt change of runoff recorded at the Huangfu hydrological station in the period from 1956 to 2009 is examined using three diagnostic methods and the results are presented in Fig. 5.

Obviously, the abrupt changes appear around 1979 and 1999, dividing the curve into three sections. The Pettitt test shows that these two points are statistically significant dividing points with $p$ values of 0.003 and 0.04 , respectively.

\subsubsection{Abrupt changes in meteorological factors}

The sequential cluster method is used to diagnose the abrupt changes in precipitation, temperature and the aridity index

Table 2 Changes of temperature, precipitation, aridity index and runoff in five periods

\begin{tabular}{lllll}
\hline Periods & $\begin{array}{l}\text { Temperature } \\
\left({ }^{\circ} \mathrm{C}\right)\end{array}$ & $\begin{array}{l}\text { Precipitation } \\
(\mathrm{mm})\end{array}$ & $\begin{array}{l}\text { Aridity } \\
\text { index }\end{array}$ & $\begin{array}{l}\text { Runoff } \\
\left(\mathrm{m}^{3} / \mathrm{s}\right)\end{array}$ \\
\hline $1956-1969$ & 6.8 & 438 & 26.1 & 6.1 \\
$1970-1979$ & 6.7 & 401 & 24 & 5.6 \\
$1980-1989$ & 6.3 & 366 & 22.5 & 4.0 \\
$1990-1999$ & 7.2 & 387 & 22.6 & 2.9 \\
2000-2009 & 7.7 & 362 & 20.5 & 1.1 \\
54-year average & 6.9 & 394 & 23.4 & 4.1 \\
\hline
\end{tabular}




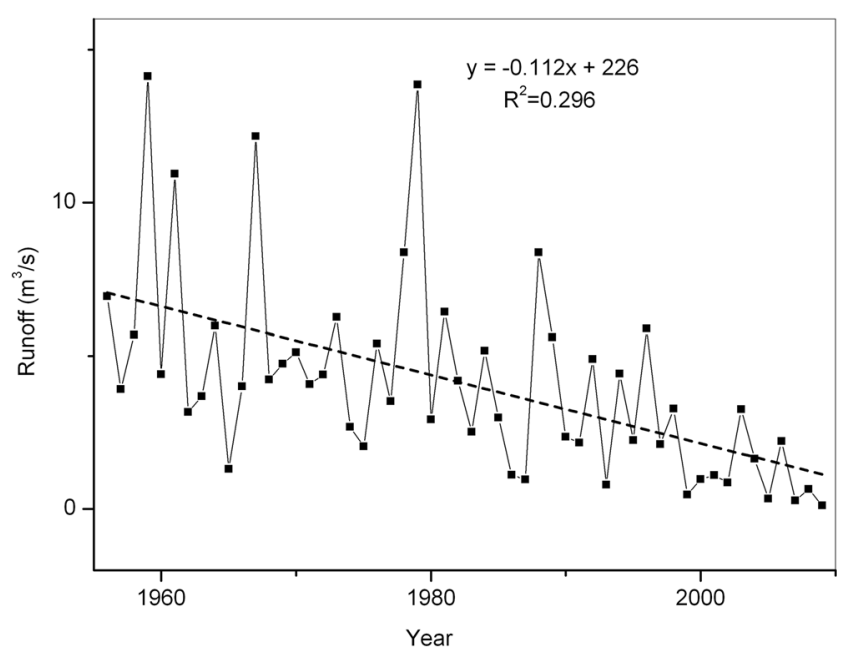

Fig. 4 Changes of annual runoff of the Huangfuchuan River from 1956 to 2009

series in the period 1956-2009 and the results are presented in Fig. 6.

Figure 6a shows the changes in $S_{\mathrm{n}}(\tau)$ of the precipitation series in the period from 1956 to 2009. An abrupt change can be recognised around 1961. By applying the sequential cluster method to the series between 1962 and 2009, another abrupt change can be identified around 1998. These two points are also found in the $S_{\mathrm{n}}(\tau)$ of the aridity index series (Fig. 6c). The changes in $S_{\mathrm{n}}(\tau)$ of the temperature series discloses two abrupt changes around 1982 and 1999 (Fig. 6b).

3.3 Impacts of climate change and anthropogenic activities on runoff

Using the available data of soil and water conservation measures and irrigation land in the period from 1959 to 2006, the relation of runoff to the aridity index and anthropogenic activities is quantified through principal components regression. The results show that the first component accounts for $69 \%$ of the total variance and the first two components for
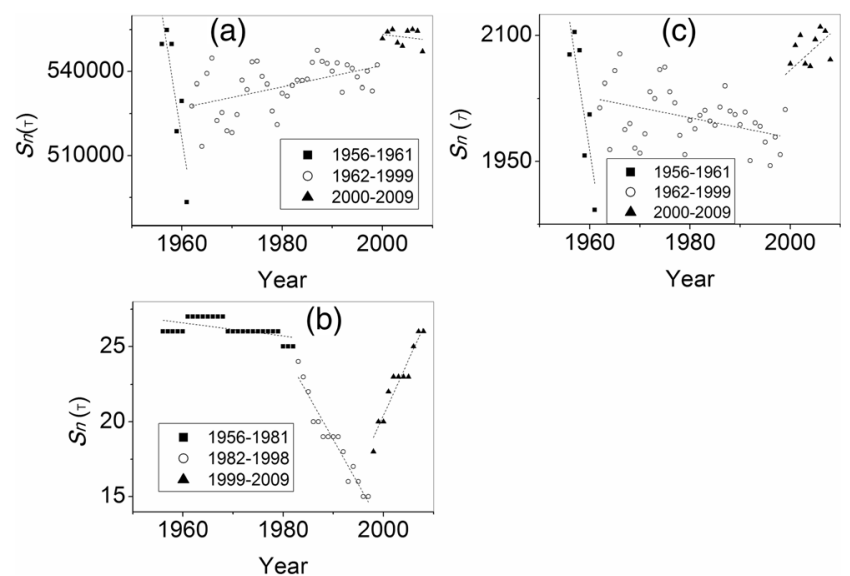

Fig. 6 Sequential cluster statistical results of the abrupt change in climate factors. a Precipitation $S_{\mathrm{n}}(\tau)$; b Temperature $S_{\mathrm{n}}(\tau)$; c Aridity index $S_{\mathrm{n}}(\tau)$

$97 \%$; therefore, two components are selected. Then, the runoff coefficient is related with the two components using multiple regression analysis. After replacing the two components with their constitutive elements, the coefficients of aridity index, and areas of soil conservation measures and irrigation in the derived relation are found to be 0.00347 , -0.267 and -6.74 , respectively.

As mentioned above, soil erosion control has been performed on a large scale in the Huangfuchuan basin up to 1979, which coincides with the first abrupt change in the annual runoff series detected by this study. For quantifying the contributions of different influencing factors to runoff variation, the period before the first abrupt change is termed the 'reference period'. The period after the first abrupt change is termed the 'measurement period', during which the runoff was influenced by both climate change and anthropogenic activities. This is divided further into two measurement periods by the second abrupt change around 1999. Using the relation of runoff coefficients to the aridity index and areas of soil conservation measures and irrigation derived above, the influences of aridity variation, soil conservation measures and irrigation in two measurement periods are established and displayed in Table 3.
Fig. 5 Statistical results of the abrupt change in runoff series. a Sequential cluster $S_{\mathrm{n}}(\tau)$; b Pettitt $K$; c Lee-Heghinian $f(\tau)$
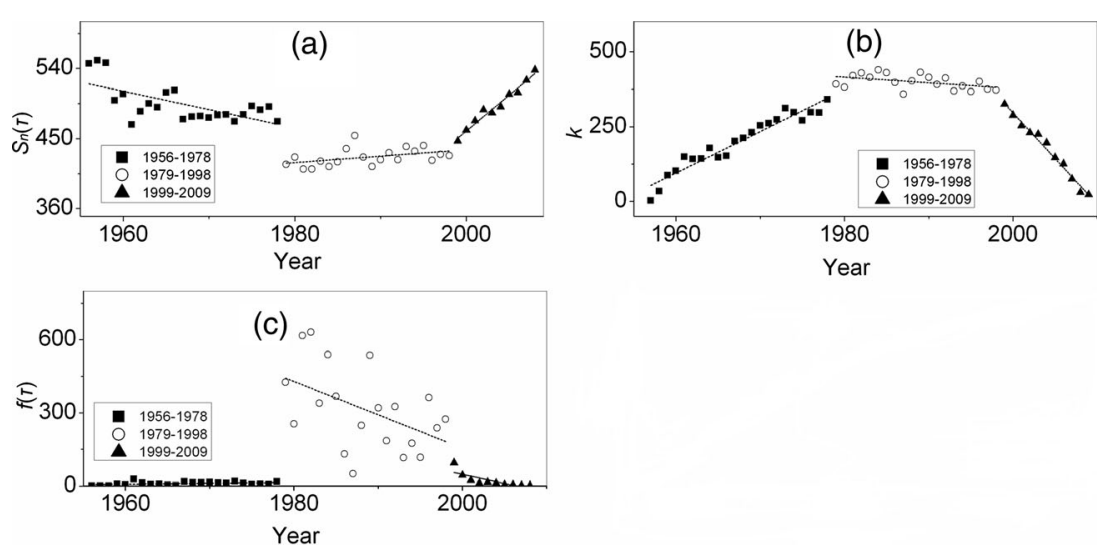
Table 3 Contribution of climate change and water use and soil conservation measures to runoff deviation

\begin{tabular}{lllll}
\hline Periods & Mean runoff $\left(\mathrm{m}^{3} / \mathrm{s}\right)$ & $\begin{array}{l}\text { Contribution of } \\
\text { climate change (\%) }\end{array}$ & $\begin{array}{l}\text { Contribution of soil } \\
\text { conservation measures (\%) }\end{array}$ & $\begin{array}{l}\text { Contribution of } \\
\text { irrigation (\%) }\end{array}$ \\
\hline Reference period & 5.53 & $/$ & $/$ & $/$ \\
The first measurement period & 4.12 & 40 & 28 & 31 \\
The second measurement period & 1.36 & 44 & 30 & 26 \\
\hline
\end{tabular}

\section{Discussion}

\subsection{Causes for occurrence of abrupt changes in runoff}

Three diagnostic methods have detected the same abrupt changes, i.e., 1979 and 1999, in the runoff series recorded at the Huangfu station during 1956 to 2009. Ran et al. (2008) and Wang et al. (2009) also found that the runoff series of the basin exhibited an abrupt change around 1979, and Wang et al. (2009) detected another abrupt change around 1996 in the runoff series from 1956 to 2005 when using a double mass curve. Hence, the existence of the two abrupt changes detected in the runoff series recorded at the Huangfu station between 1956 and 2009 can be regarded as a proven fact.

As stated above, although water and soil conservation measures have been performed in the Huangfuchuan watershed since the 1950s, it was in the 1970s that the sediment check dams were built on a large scale within the watershed. The sediment check dams not only reduced soil losses, but also, directly or indirectly, changed the river runoff. Thus, this might be the reason for the runoff changing abruptly around 1979.

The state increased the investment in soil erosion control after 1983, but this had achieved little by the end of the 1980s. To accelerate the progress of soil erosion control, soil conservation measures were implemented on a large scale after 1993. Moreover, in order to promote the restoration of local ecosystems, the programme of returning farmland to forests/grass and of protecting natural forests was launched on the Loess Plateau in 1997. This programme also had a great impact on soil erosion control and runoff generation. In addition, we detected an abrupt change in 1998 in the aridity index series. Therefore, the abrupt change in runoff around 1999 should be a reflection of the effects of climate change, the ecosystem restoration programme, and/or expanded soil conservation measures in the Huangfuchuan basin.

\subsection{Impacts of climate change and anthropogenic activities on runoff}

Table 3 shows that anthropogenic activities, including soil conservation measures and irrigation, were the most important factor affecting runoff reduction in the measurement periods. The proportion of runoff reduction caused by soil conservation measures increased from $28 \%$ in $1979-1998$ to $30 \%$ in 1999-2006. Water diversion for irrigation was the primary reason for runoff reduction related to anthropogenic activities in 1979-1998, although this declined by $5 \%$ in 1999-2006, which could be related to the projects for the restoration of the natural environment. Following the implementation of the project returning farmland to forest or grass, the areas of forest and grass increased more quickly than that of irrigation, which resulted in an increase in the percentage contribution of soil conservation measures, but a decrease in that of water diversion for irrigation during 1999-2006. Compared with anthropogenic activities, the contribution of climate change to runoff reduction is less than $50 \%$. However, with increasing climatic aridity, the contribution of climate change to runoff reduction increased from $40 \%$ in $1979-1998$ to $44 \%$ in $1999-2006$.

\section{Conclusions}

Runoff has reduced significantly in the Huangfuchuan basin over the past 50 years with two abrupt changes around 1979 and 1999. Meanwhile, climatic aridity within the basin has clearly increased with two abrupt changes around 1961 and 1998, which also occurred in the precipitation series. The first abrupt change in the annual runoff of the basin is related to the large-scale construction of sediment check dams, and the second is related to the abrupt increase of climatic aridity and the large-scale implementation of soil conservation measures and/ or ecosystem restoration. It is estimated that over half of the runoff reduction within the basin can be attributed to anthropogenic activities, of which water diversion for irrigation was the main contributor during 1979-1998. The contribution of soil conservation measures to runoff reduction increased and that of water diversion for irrigation reduced during 1999-2006, mainly due to the implementation of the project for the restoration of the natural environment. Following the increase of climatic aridity, the impact of climate change on runoff deviation within the basin increased from 1979-1998 to 1999-2006.

Acknowledgments This work was supported financially by the National Major Basic Research Program of China (grant no. 2011CB403305), the National Natural Science Foundation of China (grant no. 41371036) and International cooperative project of the Ministry of Science and Technology of China (grant no. 2013DFA91700). We are grateful to the 
anonymous reviewers for their useful comments and critiques that helped us improve the paper, and the Yellow River Conservancy Commission and the China Meteorological Administration for permission to access the hydrological and meteorological data.

\section{References}

Alan FH, Dennis PL (1999) Effects of climate change on hydrology and water resources in the Columbia River basin. J Am Water Resour Assoc 35(6):1597-1623

Alizadeh A (2001) Principles of applied hydrology, 13th edn. Astan Ghodss Publishing, Mashad

Anthony F (1999) Potential climate change impacts on water resources in the Auckland region (New Zealand). Clim Res 11:221-245

Arnell N, Bates B, Lang H, Magnuson JJ, Mulholland P (1996) Hydrology and freshwater ecology. In: Watson RT, Zinyowera MC, Moss RH (eds) Climate change 1995-impacts, adaptations and mitigation of climate change: scientific-technical analyses. Contribution of Working Group II to the Intergovernmental Panel on Climate Change Second Assessment Report. Cambridge University Press, Cambridge, pp 325-363

Barnett TP, Adam JC, Lettenmaier DP (2005) Potential impacts of a warming climate on water availability in snow-dominated regions. Nature 438:303-309

Chen XR, Zhang ZH, Cai Y (2013) Review of the climate change in recently one hundred years and the potential natural factors affected. Mar Forecasts 30(1):78-85

Cox DR, Stuart A (1955) Some quick sign tests for trend in location and dispersion. Biometrika 42:80-95

De Martonne E (1926) Aérisme et indice d'aridité. C R Acad Sci 182: $1395-1398$

Ding J (1986) Statistical detection for transition point in flood time sequences. J Wuhan Univ Hydraul Electr Eng (5):36-40 (in Chinese)

Edossa DC, Babel MS, Gupta AD (2010) Drought analysis in the Awash River Basin, Ethiopia. Water Resour Manag 24(7):1441-1460

Ferre L (1995) Selection of components in principal component analysis: a comparison of methods. Comput Stat Data Anal 19:669-682

Frederick KD, Major DC (1997) Climate change and water resources. Clim Chang 37:7-23

Gao QZ, Jiang Y, Li LY (2005) Analysis on climate change of Huangfuchuan watershed in the middle Yellow River. J Arid Land Resour Environ 19(1):116-121 (in Chinese)

Grafton RQ, Pittock J, Davis R, Williams J, Fu GB, Warburton M, Udall B, McKenzie R, Yu XB, Che N, Connell D, Jiang Q, Kompas T, Lynch A, Norris R, Possingham H, Quiggin J (2013) Global insights into water resources, climate change and governance. Nat Clim Chang 3:315-321

Guardiola CM, Troch PA, Breshears DD, Huxman TE, Switanek MB, Durcik M, Cobb NS (2011) Decreased streamflow in semi-arid basins following drought-induced tree die-off: a counter-intuitive and indirect climate impact on hydrology. J Hydrol 406(3-4):225233

Houghton DD (2007) Global climate change — basics, challenges, and international impacts. Brewer Public Library, Richland Center

Houghton JT, Meira Filho LG, Griggs DJ, Maskell K (1997a) An introduction to simple climate models used in the IPCC second assessment report - IPCC Technical Paper II

Houghton JT, Meira Filho LG, Griggs DJ, Maskell K (1997b) Stabilization of atmospheric greenhouse gases: physical, biological and socio-economic implications - IPCC Technical Paper III

Jiang Y, Kang MY, Gao QZ, He LH, Xiong M, Jia ZB, Jin ZP (2003) Impact of land use on plant biodiversity and measures for biodiversity conservation in the Loess Plateau in China - a case study in a hilly-gully region of the northern Loess Plateau. Biodivers Conserv 12(10):2121-2133

Jim G (2006) Water crisis happening now. Nature. doi:10.1038/ news060821-1

Jolliffe IT (1986) Principal component analysis. Springer, New York

Kendall MG (1975) Rank correlation methods. Charles Griffin and Co. Ltd., London

Lee AFS, Heghinian SM (1977) A shift of the mean level in a sequence of independent normal random variable: a Bayesian approach. Technometrics 19(4):503-506

Li LJ, Zhang L, Wang H, Wang J, Yang JW, Jiang DJ, Li JY, Qin DY (2007) Assessing the impact of climate variability and human activities on streamflow from the Wuding River basin in China. Hydrol Process 21(25):3485-3491

Liu Q, Cui BS (2011) Impacts of climate change/variability on the streamflow in the Yellow River basin, China. Ecol Model 222(2): 268-274

Lungu M, Panaitescu L, Niță S (2011) Aridity, climatic risk phenomenon in Dobrudja. Present Environ Sustain Dev 5(1):179-189

Magadza CHD (2000) Climate change and human settlements in Africa: prospects for adaptation. Environ Monit Assess 61(1):193-205

Mall RK, Gupta A, Singh R, Singh RS, Rathore LS (2006) Water resources and climate change: an Indian perspective. Curr Sci India 90(12):1610-1626

Mann HB (1945) Non-parametric test against trend. Econometic 13(3): 245-259

Middelkoop H, Daamen K, Gellens D, Grabs W, Kwadijk JCJ, Lang H, Parmet BWAH, Schadler B, Schulla J, Wilke K (2001) Impact of climate change on hydrological regimes and water resources management in the Rhine basin. Clim Chang 49(1-2):105-128

Mu XM, Basang C, Zhang L, Gao P, Wang F, Zhang XP (2007) Impact of soil conservation measures on runoff and sediment in HekouLongmen region of the Yellow River. J Sediment Res (2):36-41 (in Chinese)

Neira Mendez FH (2005) Assessment of climate indices in drylands of Colombia. Dissertation, University of Universiteit Gent

Niklas SC, Andrew WW, Nathalie V, Dennis PL, Richard NP (2004) The effects of climate change on the hydrology and water resources of the Colorado River basin. Clim Chang 62(1-3):337-363

Oliver JE (2005) The encyclopedia of world climatology. Springer, Netherlands

Pettitt AN (1979) A non-parametric approach to the change point problem. Appl Stat 28(2):126-135

Ran DC (2006) Water and sediment variation and ecological protection measures in the middle reaches of the Yellow River. Resour Sci 28(1):93-100 (in Chinese)

Ran DC, Luo QH, Zhou ZH, Wang GQ, Zhang XH (2008) Sediment retention by check dams in the Hekouzhen-Longmen section of the Yellow River. Int J Sediment Res 23(2):159-166

Revelle RR, Waggoner PE (1983) Effects of a carbon dioxide-induced climatic change on water supplies in the western United States. Chang Clim 8211:419-432

Rogers P (2008) Facing the freshwater crisis. Sci Am 299:46-53

Sui J, He Y, Karney BW (2008) Flow and high sediment yield from the Huangfuchuan watershed. Int J Environ Sci Technol 5(2):149-160

Tang GL, Ding YH, Wang SW, Ren GY, Liu HB, Zhang L (2009) Comparative analysis of China surface air temperature series for the past 100 years. Adv Clim Chang Res 5(2):71-78

Wang AJ, Zhu C (2002) Response of water break-off in the Yellow River to global climate change. J Nat Disasters 11(2):103-107 (in Chinese)

Wang L, Xia J, Zhang XC (2006a) Cause analysis of Wuding River flow decline in 1990s. J Basic Sci Eng 14(4):463-469 (in Chinese)

Wang Y, Cao MK, Tao B, Li KR (2006b) The characteristics of spatiotemporal patterns in precipitation in China under the background of global climate change. Geogr Res 25(6):1031-1040 
Wang XJ, Cai HJ, Zhang X, Wang J, Zhai JF (2009) Analysis of changing characteristics and tendency of runoff and sediment transport in Huangfuchuan River watershed. Res Soil Water Conserv 16(1): 222-226 (in Chinese)

Wang JH, Zhang SL, Sun WY, Huang J (2011) Recent sediment reduction benefits of soil and water conservation measures adopted in Huangfuchuan River basin. Soil Water Conserv China (3):57-60 (in Chinese)

Water Resources Council (U.S.) (1978) The nation's water resources: the second national water assessment. U.S. Govt. Printing Office, Washington, D.C.

Woodhouse CA, Overpeck JT (1998) 2000 years of drought variability in the central United States. Bull Am Meteorol Soc 79(12):2693-2714

$\mathrm{Xu}$ CY (2000) Modeling the effects of climate change on water resources in Central Sweden. Water Resour Manag 14:177-189

Xu JX (2004) Response of erosion and sediment producing processes to soil and water conservation measures in the Wudinghe River basin. Acta Geograph Sin 59(6):972-981 (in Chinese)

Xu JX (2011) Variation in annual runoff of the Wudinghe River as influenced by climate change and human activity. Quat Int 244(2):230-237

Xu JX, Wang HB (2010) Influence of soil and water conservation measures on reducing in frequency of hyperconcentrated flows in the Wudinghe River basin. Environ Earth Sci 62(7):1513-1520

$\mathrm{Xu} \mathrm{H}$, Taylor RG, Xu Y (2011) Quantifying uncertainty in the impacts of climate change on river discharge in sub-catchments of the Yangtze and Yellow River basins, China. Hydrol Earth Syst Sci 15:333-344
Yin YH, Wu SH, Chen G (2009) Regional difference of climate trend and abrupt climate change in China during 1961-2006. J Nat Resour 24(12):2147-2157

Yue S, Pilon P, Phinney B, Cavadias G (2000) The influence of autocorrelation on the ability to detect trend in hydrological series. Hydrol Process 16(9): 1807-1829

Zarghami M, Abdi A, Babaeian I, Hassanzadeh Y, Kanani R (2011) Impacts of climate change on runoffs in east Azerbaijan, Iran. Glob Planet Chang 78(3-4):137-146

Zhang SL, Yu YM, Yao WY (1994) The calculation methods of the effects of water and soil conservation measures on water and sediment reduction. China Environmental Science Press, Beijing (in Chinese)

Zhang JY, Wang GQ, He RM, Liu CS (2009) Variation trends of runoffs in the middle Yellow River basin and its response to climate change. Adv Water Sci 20(2):153-158 (in Chinese)

Zhang SH, Liu SX, Mo XG, Shu C, Zheng CL, Hou B (2010) Impacts of precipitation variation and soil and water conservation measures on runoff and sediment yield in the Wuding River basin, middle reaches of the Yellow River. J Beijing For Univ 32(4):161-168 (in Chinese)

Zhi L, Liu WZ, Zhang XC, Zheng FL (2009) Impacts of land use change and climate variability on hydrology in an agricultural catchment on the Loess Plateau of China. J Hydrol 377(1-2):35-42

Zhu QW, Fan WH, Ru YY, Xing GY (2003) Analysis on runoff and sediment reduction through soil and water conservation measures conducted in Huangfuchuan River basin. Yellow River 25(9):26-27 (in Chinese) 